\title{
English as a Language Medium of Teaching Mathematics in Jordanian Primary
} Schools

\author{
Maisa Saadi Jaber ${ }^{1}$ \\ Hana Asaad Daana²
}

Princess Alia University College /Al-Balqa Applied University, Jordan

Email:mais jaber@hotmail.com Tel.+962799999333

Email: hana97us@yahoo.com Tel: +962777728089

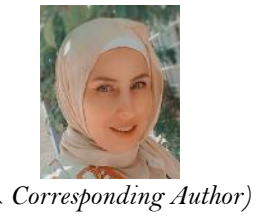

\begin{abstract}
It is agreed that, if instruction in mathematics takes place in the students' first language, understanding abstract concepts and ideas in that subject can be challenging for them. However, many Jordanian students must master mathematics only via a second language or side by side with mastering it in Arabic, depending on their school system. The present study investigated the effect of using a second language to teach mathematics in international Jordanian schools. The study conducted a contrastive analysis of the strategies used in teaching mathematics in Jordanian schools. The researchers prepared a mathematics test with the assistance of a mathematics teacher. The test consisted of three-word questions whose complexity ranged between simple calculations to complex calculations. Data were collected from eighty students in Grade 7. Forty of the students were from a school which starts teaching mathematics only in Arabic - the students' first language - and then in Grade 7, it introduces mathematics in English; alternatively, the other forty were from a school which teaches mathematics in English straight from Grade 1. The result shows that the language medium has an essential role in the teaching process. The study reveals significant differences between the two groups; the students who are taught mathematics in Arabic first tend to be more skillful and accurate answering the mathematical problems than those who are taught mathematics in English from Grade 1.
\end{abstract}

Keywords: Mathematics, First language, Second language, Language medium, Jordanian schools, Contrastive analysis

Citation | Maisa Saadi Jaber; Hana Asaad Daana (2020). English as a Language Medium of Teaching Mathematics in Jordanian Primary Schools. Journal of Education and e-Learning Research, 7(3): 258262.

\section{History:}

Received: 15 May 2020

Revised: 30 June 2020

Accepted: 8 August 2020

Accepted: 3 August 2020

Published. 10 August $2020-1$.

Attribution 3.0 License (cc)

Publisher: Asian Online Journal Publishing Group
Acknowledgement: Both authors contributed to the conception and design of the study.

Funding: This study received no specific financial support.

Competing Interests: The authors declare that they have no conflict of interests.

Transparency: The authors confirm that the manuscript is an honest, accurate, and transparent account of the study was reported; that no vital features of the study have been omitted; and that any discrepancies from the study as planned have been explained.

Ethical: This study follows all ethical practices during writing.

\section{Contents}

1. Introduction

. Related Studies....

References... 


\section{Contribution of this paper to the literature}

This paper is the first to investigate the effect of using the English Language to teach Jordanian students mathematics and science. No previous research has been conducted on this issue. Therefore, this paper is expected to reveal the effect(s) of using English as the language medium of teaching mathematics in Jordanian primary-schools.

\section{Introduction}

Teaching in Jordan is a developed process with upgraded systems. Many schools have chosen English as a second language to be the medium of instruction instead of the native Arabic language. We expect that this phenomenon of teaching mathematics and science in English in Jordan is to ensure that the Jordanian community can keep abreast of scientific and technological teaching methods and to increase the students' proficiency in English. The effect of the use of a second language to teach school subjects to non-native students has been a topic of increased concern to educators as well as psycholinguists (Bernstein, 1960; Bernstein, 1961; Bialystok, 2004; Bostwick, 1999; Bruck, Lambert, \& Tucker, 1977; Goddard, 1917; Lapkin, Swain, \& Shapson, 1990; Peal \& Lambert, 1962; Picard, 2004; Saer, 1923; Saer, 1922; Smith, 1939). In Jordan, our concern of investigating the effect of using English as the language of medium to teach mathematics in Jordanian International Primary schools is in part because of a continuing growth in the number of students enrolling in international schools (Jordan in Figures, 2018). It is expected that many students who received their schooling in the National Programme and who move to universities to major in scientific fields at universities and colleges will encounter problems related to scientific courses being taught in English such as mathematics, physics, chemistry and others. This requires investigation, though. Statistically, there are 57 schools in Jordan applying the international system in teaching. Fifty-three of these schools are in the Jordan's capital city of Amman, one school is in Irbid, and three schools are in Aqaba. The international systems used in these schools are different from one school to another. Not only are SAT, IG and IB the three main international teaching systems applied to Jordanian schools, but there are also three different main strategies used by those schools.

Some international schools use the English language to teach all subjects excluding Arabic from Grade 1. Other schools are considered bilingual schools, as they teach all subjects -mathematics, science and social studies in both Arabic and English. The subjects of Arabic Language and religion are the exception as they are taught in Arabic only. The third group of schools is the international schools in which students learn all subjects in Arabic until a certain grade. Starting around puberty they learn these main subjects in English. It is worth mentioning that these schools also teach English as a second language, but they do not consider it as a means to teach any other subject until the age of puberty.

\section{Related Studies}

Second Language Acquisition (SLA) is a process of learning a second language (L2) in addition to the students' mother tongue (Collins Dictionary). Collins Dictionary defines a Second Language as the language that a person learns after his/her native language (Collins Dictionary). Learning or acquiring a second language can be achieved formally in a classroom environment in schools. A second language can also be learned in an informal way; that is when the learner acquires the language by being an active participant in a society. This can be done by watching local television, listening to radio and/or reading newspapers in L2 (Bahrani, Sim, \& Nekouei, 2014).

Initially, Krashen (1982) stated that an adult acquires a second language by learning it consciously, through explicit formal linguistic knowledge of the language, while, children acquire their first language subconsciously through informal and implicit learning. Once you have acquired something like a second language, you are not always aware that you have done so. It just feels natural or as if it has always been there.

The process of second language acquisition is complex and unique. It depends upon social and biological factors and differs from first language acquisition. Ingram (1989) and Harley (1986) posited that there are differences between first and second language acquisition in terms of cognitive development, context used for each language, stages, and psychological and physiological differences between adults and children.

It is worth mentioning here that there have always been two stances regarding the relationship between bilingualism and cognitive capacities at the child's early age. One group of researchers offers arguments against bilingualism at early ages (Bernstein, 1960; Bernstein, 1961; Goddard, 1917; Saer, 1923; Saer, 1922; Smith, 1939) while the other group of researchers offers evidence of the beneficial effects of bilingualism at early ages (Bialystok, 2004; Bostwick, 1999; Bruck et al., 1977; Lapkin et al., 1990; Peal \& Lambert, 1962; Picard, 2004; Steinberg \& Sciarini, 2006).

To start with, many opponents of bilingualism at early ages claim that exposing young learners to a second language might have a detrimental effect on the cognitive development of children. They also believe that bilingualism may have negative influence on the intellectual processes children such as in the subject of mathematics (Steinberg \& Sciarini, 2006).

Saer (1923) tested the intelligence of 1,400 bilingual children in Wales. Comparing his subjects' results to the higher scores achieved by monolingual children on intelligence tests, he found that the thinking processes of bilinguals were confused. He attributed this confusion to the fact that they were using two languages.

In addition, there appears to be a direct relationship across various school subjects between instruction in the student's native language and high achievement in the subject. Gaarder (1975) argues that the use of English as the language of the test is one reason for the low achievement scores of Hispanic students.

Holland (1960); Meeker and Meeker (1973) and Mycue (1968) found that when tests were translated, Hispanic students tended to do better on the Spanish version (their native language) than on the English version.

Concerning mastering mathematics, the process is considered to be a two-step process: First, students have to understand mathematical concepts (Richards, 1982; Thurston, 1995) and secondly, they have to be able to communicate their understanding of these concepts in written format (Brown, 1994). The lecturer clarifies concepts by using two verbal languages: a commonly spoken, everyday language and a subject-specific, scientific language. Therefore, the student must be proficient in both these languages. However, competence in the former does not 
imply competence in the latter (Lemke, 1990). Gee (2015) concludes that mathematical discourses are not only ways of talking, acting, interacting, thinking, believing, reading, and writing, but also communities, values, beliefs, points of view, objects, and gestures.

Bohlmann (2001) also stated that bilingualism and education are a double task. It entails the acquisition of two conceptually difficult and different skills at once - one being related to language and the other to mathematical concepts in mathematical contents. Rollnick (2000) rightly stated that learning a new and a difficult subject by the medium of a second language is considered to be unreasonable for the need of mastering them is a double task where they have to master the scientific contents and the language. However, he further argued that proficiency in conversational English is not the only prerequisite for students whose second language is English to master mathematics. They also need to be familiar with scientific English, which also leads those learners to learn a new language while learning science.

Far to the other extreme is the second stance concerning the relationship between bilingualism and the cognitive processes of children, which claims that there are a number of advantages of being exposed to a second language, including cognitive advantages that can arise from achieving a particular level of proficiency in a second language (Bialystok, 2004; Bostwick, 1999; Brown., 2006; Bruck et al., 1977; Cossio, 1977; Kamal, 2019; Lapkin et al., 1990; Manuel \& Wright, 1929; Peal \& Lambert, 1962; Picard, 2004; Steinberg \& Sciarini, 2006). For centuries, it has been acknowledged that learning about other peoples, other cultures and other languages broadens the mind. Historically, individuals were exposed to languages such as Latin and Greek in schools to give them access to rich literature and to deeper appreciation of the history and structure of the English language. Latin and Greek were considered the languages of books and of higher education. Hence, it was essential for those who wanted to pursue their higher education to learn one or both languages (Brown, 2006; Tong \& Baslom, 2019).

Cossio (1977) who found a positive correlation between mathematics achievement and second-language ability attested to the positive relation between bilingualism and mathematical achievement. Manuel and Wright (1929) however, found no difference in the performance of children on the Spanish and English versions of mathematics achievement tests.

Bruck et al. (1977) conducted a long-term study with native English-speaking children learning French as a second language. They found out that those bilingual children performed better than the English monolingual children on creativity tests and mathematics.

Bostwick (1999) conducted a comparative study on two groups of Japanese students in the same elementary school. The first group consisted of children learning through the medium of Japanese. The second group consisted of children learning the school curriculum through the medium of English. He found out that the group exposed to two languages presented the same results as the monolingual group in their academic achievement. In their study, Peal and Lambert (1962) concluded that bilingualism improved thinking.

Thurston (1995) suggests that the effective communication of mathematical ideas is the key. Language forms an integral part of this communication. McLean (2000) supports Thurston's view by claiming that inadequate knowledge of the basic vocabulary could be a reason for many learning problems. Conducting studies on bilingual African students, Rollnick (2000) and Bohlmann (2001) claimed that the being bilingual could be an advantage for students in their studies, enabling them to see different representations of a single idea.

\section{Purpose of the Study}

As we could see in the Related Studies section above, cusing a second language as the language medium during the early years of schooling has always been a debatable issue in several studies. Most scholars argued strongly for using the students' native language as the language medium. Thus, when a second language is chosen to be a language medium in the early schooling years, it contradicts this almost unanimously agreed upon notion of the mother tongue as the best language medium to begin education at primary schools. Hence, one may conclude that using a second language as a language medium during the early years of schooling might inevitably have two facets. It could cause learning difficulties because of the language barrier, or it could be an advantage for the cognitive development of learners.

The present study investigated the effect of using a second language to teach mathematics in international Jordanian schools. While there are three systems for teaching mathematics in schools, students' achievements may differ from one system to another depending on different factors. The focus of this study and the factor under consideration here was the influence of the second language on the perception of mathematical concepts in two of the three systems: 1) schools, which teach all subjects in a second language, e.g., English right from, Grade 1, and 2) schools, which start teaching the scientific subjects in English from Grade 6. Data was analyzed and tabulated and discussed. The discussion was then followed by a comparison between these two systems.

\section{Methodology}

The data excerpts quoted in this article have been taken from a test in mathematics. The test was distributed to eighty students in Grade 7 in two different schools. Each school has different teaching system. The test consisted of three verbal problems or word problems that needed four different mathematical processes for solving them: multiplication, division, subtraction and addition. So, to find the answer, the students had first to understand the question, imagine the situation and then start looking for the suitable process to solve the question. After reading each question, the students were asked to answer it without any help from their instructors. They were given seven minutes to answer each question.

The questions were corrected by the researchers, taking into consideration three aspects. Firstly, the researchers comprehended the problem to know whether the student would understand it fully or partially, to measure their English language proficiency. Secondly, the researchers considered the students' calculation mistakes, to measure their conceptual proficiency of the mathematical terms. The last aspect was the time needed to answer each question to compare the students' fluency.

Data was collected from forty sixth graders from two different schools. The first school teaches mathematics only in English right from the first grade (school A). The second school teaches mathematics in Arabic from Grade 
1 to Grade 5. Then it shifts to teach mathematics only in English at Grade 6. The names of the schools were not mentioned as per their request.

\section{Data Analysis and Discussion}

For this study, data were analyzed both qualitatively and quantitatively. The subjects' answers were analyzed using descriptive statistics. Their achievements in the test were calculated using percentages.

The first addressed research question was:

1) Lynette saves $\$ 40$ per week for her vacation. Her goal is to save $\$ 1,200$. If she has been saving for 18 weeks, how many more weeks must she save to meet her goal?

Table 1, presents the percentages of the calculation of the students' performance in the first word problem:

\begin{tabular}{c|c|c|c}
\multicolumn{5}{|c}{ Table-1. Data analysis of the responses to the first question in percentages } \\
\hline School & Understanding the problem & Calculations mistakes & Time needed \\
\hline A & $60 \%$ & $75 \%$ & 7 min. \\
\hline B & $80 \%$ & $72 \%$ & 4 min. \\
\hline
\end{tabular}

Table 1 above indicates that there were some differences regarding the achievement of students from both schools. Even if the difference was sometimes insignificant, it must be taken into consideration. School A. which teaches mathematics only in English from Grade 1, had a lower percentage for fully comprehending the word problem. These students understood part of the question. They knew what was required, but their problem was how to relate things together and especially in the correct order; for that reason, they sometimes asked their teachers for clarification. They needed more time to answer this question.

On the other hand, school B students who had learned mathematics in Arabic then switched to the second language of English only in Grade 6 were more flexible and relaxed while answering, asked fewer questions, and took less time to solve the problem presented. They were more skillful in relating the data with the correct calculations in the correct order.

Taking into consideration the differences between students, the second question in this study was a little bit easier than the first one:

2) There are 23 pancakes on the griddle at a restaurant. The chef places 4 pancakes on each order. How many orders can the chef fill, and how many pancakes must be added to those remaining to make another order?

Table 2, below, presents the percentages of the students' performance in the second word problem:

\begin{tabular}{c|c|c|c}
\multicolumn{4}{|c}{ Table-2. Data analysis of responses to the second question in percentages } \\
\hline School & Understanding the problem & Calculations mistakes & Time needed \\
\hline A & $85 \%$ & $82 \%$ & $5 \mathrm{~min}$. \\
\hline B & $90 \%$ & $80 \%$ & $4 \mathrm{~min}$. \\
\hline
\end{tabular}

Firstly, Table 2 shows that, the students found the second question easier than the first one, and especially the first part of the question in which they need to know the number of orders which could be filled. As for the second request (the remaining pancakes to make another order), they hesitated and thought more about it, especially school A, but this part of the question took no more than one minute to be answered by almost all of the students.

The last question in the present study was the most difficult one as this question needs more attention and accuracy on the part of the students than the first two-word problems.

3) Pencils are on sale at Office Emporium for $\$ 2.50$ per dozen. Ms. Klein buys 4 pencils for each of her 50 students. How much will she spend on pencils?

This word problem is considered the most difficult word problem out of the three. It needed higher cognitive skills because the students needed to first imagine the situation. Then, they needed to understand the meaning of "dozen" and relate it to the rest of the numbers. After that, they needed to think about the total number of pencils to know how much she would spend on them in the end. Table 3, presents the details in percentages:

\begin{tabular}{c|c|c|c}
\multicolumn{4}{|c}{ Table-3. Data analysis of responses to the third question in percentages } \\
\hline School & Understanding the problem & Calculations mistakes & Time needed \\
\hline A & $67 \%$ & $66 \%$ & 7 min. \\
\hline B & $81 \%$ & $70 \%$ & 5 min. \\
\hline
\end{tabular}

The percentages in Table 3 show that the third question is more difficult than the other two. Moreover, some of the students did not complete the question (four from school A and two from school B). Additionally, they needed more time to solve it. Interestingly, students from school B were mostly the ones who asked about the significance and the meaning of the word "dozen", while students from school A understood that "dozen" means "twelve".

Although the questions of the study have different levels of difficulty, the three tables in general show convergent results. The school using the first language system for teaching mathematics has higher percentages than the school that teaches mathematics in English (the second language in Jordan). It's not only the three questions that are more intelligible to students from school B, but also it's the fact that school B needed less time to answer the questions but committed more calculation mistakes because the students answered without reflecting and by being overconfident.

\section{Conclusion}

The choice of language medium and system to teach mathematics and other scientific courses is a highly contested issue in primary schools, as could be seen throughout the study. Teaching mathematics in English in the Jordanian primary schools involves three different models: teaching mathematics using the mother language then 
shifting to teaching the subject in English, teaching mathematics using only English, the second language in Jordan, and the bilingual model in which mathematics is taught in Arabic, the first language, beside mathematics courses in English. The current study compared the first two methods or models.

This study tackles two different mathematics teaching systems in two different schools in Jordan. The analysis showed that students who started learning mathematics using their first language have better performance. Consequently, the students' native language is considered the best language medium for teaching scientific subjects including mathematics at primary schools.

This study makes it clear that when the language medium is a second language by which students in primary schools are taught scientific subjects, the performance of students degrades. This is because they need to focus on the language and on the material they need to learn. Given the fact that second language is often the children's weaker language in most cases, it follows that they do not possess the required mathematical management and language skills. In conclusion, the achievement of students is affected by the choice of language medium in primary schools. More precisely, the use of a second language during the early years of education might cause some difficulties in learning as the mother language is advocated as the best language medium.

\section{References}

Bahrani, T., Sim, T., \& Nekouei, Z. (2014). Second language acquisition in informal settings. Theory and Practice in Language Studies, 4(8), 1714-1723. Available at: 10.4304/tpls.4.8.1714-1723.

Bernstein, B. (1960). Language and social class. British Journal of Sociology, 11(3), 271-276. Available at: https://psycnet.apa.org/doi/10.2307/586750.

Bernstein, B. (1961). Social structure, language and learning. Educational Research, 3(3), 163-176. Available at: https://doi.org/10.1080/0013188610030301.

Bialystok, E. (2004). The impact of bilingualism on language and literacy development. In T.K.Bhatia and W.C. Ritchie (eds), The Handbook of Bilingualism. Malde, MA: Blackwell.

Bohlmann, C. (2001). Reading skills and mathematics. Paper presented at the Communications: Third Southern Hemisphere Symposium on Undergraduate Mathematics Teaching.

Bostwick, M. (1999). A study of an elementary English language immersion school in Japan. Unpublished Doctoral Dissertation Temple University, Philadelphia.

Brown, T. (1994). Towards a hermeneutical understanding of mathematics and mathematical learning. In P. Ernest (Ed.),Constructing Mathematical Knowledge: Epistemology and Mathematics Education (pp. 141-150). London: Flamer.

Brown, D. (2006). Principles of language : Learning and teaching. Longman: U.S.A: Pearson.

Bruck, M., Lambert, W. E., \& Tucker, G. R. (1977). Cognitive consequences of bilingual schooling: The St. Lambert project through grade six. Linguistics, 15(187), 13-34. Available at: https://doi.org/10.1515/ling.1977.15.187.13.

Cossio, M. J. G. (1977). The effects of language on mathematics placement scores in metropolitan colleges. Unpublished Doctoral dissertation Columbia University, Newyork.

Gaarder, A. B. (1975). Bilingual education: Central questions and concerns. New York University Education Quarterly, 6(4), 2 -6.

Gee, J. (2015). Social linguistics and literacies: Ideology in discourses. London and New York: Routledge Press.

Goddard, H. (1917). Mental testsand the immigrant. Journal of Delinquency, 2(5), 243-277.

Harley, B. (1986). Age in second language acquisition. England: Multilingual Matters.

Holland, W. R. (1960). Language barrier as an educational problem of Spanish-speaking children. Exceptional Children, 27(1), 42-50. Available at: https://doi.org/10.1177/001440296002700108.

Ingram, D. (1989). First language acquisition: Method, description and explanation: Cambridge University Press.

Kamal, S. M. (2019). Developing EFL learners vocabulary by reading English comprehension in EFL classroom. International Journal of English Language and Literature Studies, 8(1), 28-35. Available at: 10.18488/journal.23.2019.81.28.35.

Krashen, S. (1982). Principles and practice in second language acquisition. Oxford: Pergamon.

Lapkin, S., Swain, M., \& Shapson, S. (1990). French immersion research agenda for the 90s. Canadian Modern Language Review, 46(4), 638674. Available at: https://doi.org/10.3138/cmlr.46.4.638.

Lemke, J. L. (1990). Talking science: Language, learning and values. Norwood. New Jersey: Ablex Publishing Corporation.

Manuel, H. T., \& Wright, C. E. (1929). The language difficulty of Mexican children. The Pedagogical Seminary and Journal of Genetic Psychology, 36(3), 458-468. Available at: https://doi.org/10.1080/08856559.1929.10532203.

McLean, A. (2000). The predictive approach to teaching statistics. Journal of Statistics Education, 8(3).

Meeker, M., \& Meeker, R. (1973). Strategies for assessing intellectual patterns in blacks, anglo, and Mexican-American boys-or any other children-and implications for education. Journal of School Psychology, 11, 341 -350. Available at: https://doi.org/10.1016/00224405(93)90048-n.

Mycue, E. (1968). Testing in Spanish and the subsequent measurement of English fluency. Published MA Thesis Denton, TX: Texas Woman's University.

Peal, E., \& Lambert, W. E. (1962). The relation of bilingualism to intelligence. Psychological Monographs: General and Applied, 76(27), 1-23. Available at: https://doi.org/10.1037/hoo93840.

Picard, A. (2004). Bilingual older adults found to stay sharper longer. Globe and Mail, June 14, A2.

Richards, P. (1982). Difficulties in learning mathematics. Teaching mathematics. Nichols Publishing Company: London.

Rollnick, M. (2000). Current issues and perspectives on second language learning of science. Studies in Science Education, 35(1), 93-121. Available at: https://doi.org/10.1080/03057260008560156.

Saer, D. J. (1923). The effect of bilingualism on intelligence. British Journal of Psychology: General Section, 14(1), 25-38. Available at: https://doi.org/10.1111/j.2044-8295.1923.tb00110.x

Saer, D. J. (1922). An inquiry into the effect of Bilingualism upon the intelligence of young children. Journal of Experimental Pedagogy E Training College Record, 6, 232-240.

Smith, M. (1939). Some light on the problem of bilingualism as found from a study of the progress in mastery of English among children of Non-American ancestry in Hawaii. Genetic Psychology Monographs, 21, 121-284.

Steinberg, D., \& Sciarini, N. (2006). An introduction to psycholinguistics. U.K: Pearson Education Limited.

Thurston, W. P. (1995). On proof and progress in mathematics. For the Learning of Mathematics, 15(1), 29-37. Available at: https://doi.org/10.1007/0-387-29831-2_3.

Tong, S., \& Baslom, M. M. M. (2019). Knowledge management (KM) practices in education and learning: Establishing a knowledge Economy in Saudi Arabia. Humanities and Social Sciences Letters, 7(1), 1-9. Available at: 10.18488/journal.73.2019.7 1.1.9. 